$4 \quad$ Article type : Regular Paper

5

6

\title{
Four days of simulated shift work reduces insulin sensitivity in humans
}

R. Bescos ${ }^{1,2}$, M. J. Boden ${ }^{3,5}$, M. L. Jackson ${ }^{4,6}$, A. J. Trewin ${ }^{1,7}$, E. C. Marin ${ }^{1}$, I. Levinger ${ }^{1}$, A. Garnham ${ }^{8}$, D. S. Hiam ${ }^{1}$, F. Falcao-Tebas ${ }^{1}$, F. Conte ${ }^{1}$, J. A. Owens ${ }^{3}$, D. J. Kennaway ${ }^{3}$, G. K. McConell ${ }^{1}$

${ }^{1}$ Institute of Sport, Exercise and Active Living (ISEAL), Victoria University, Melbourne, Victoria, Australia.

${ }^{2}$ Institute of Health \& Community, Faculty of Health \& Human Sciences, University of Plymouth, Plymouth, United Kingdom.

${ }^{3}$ Robinson Research Institute and Adelaide School of Medicine, University of Adelaide, Adelaide, South Australia, Australia.

${ }^{4}$ College of Arts, Victoria University, Melbourne, Victoria, Australia.

${ }^{5}$ INC Research, Hindmarsh, South Australia, Australia.

${ }^{6}$ School of Health and Biomedical Sciences, RMIT University, Bundoora, Victoria, Australia.

${ }^{7}$ Department of Anesthesiology, University of Rochester Medical Center, Rochester, New York, United States of America

${ }^{8}$ School of Exercise and Nutrition Sciences, Deakin University, Melbourne, Australia.

Short title: Simulated shift work and insulin Sensitivity

Corresponding author:

This is the author manuscript accepted for publication and has undergone full peer review but has not been through the copyediting, typesetting, pagination and proofreading process, which may lead to differences between this version and the Version of Record. Please cite this article as doi: 10.1111/apha.13039

This article is protected by copyright. All rights reserved 
D. J. Kennaway, Robinson Research Institute and Adelaide School of Medicine, University of Adelaide, Adelaide, South Australia, Australia. Email: david.kennaway@adelaide.edu.au

\begin{abstract}
Aim: The aim of this study was to investigate the effects of four consecutive simulated night shifts on glucose homeostasis, mitochondrial function and central and peripheral rhythmicity compared with a simulated day shift schedule.
\end{abstract}

Methods: Seventeen healthy adults (8M:9F) matched for sleep, physical activity, and dietary/fat intake participated in this study (night shift work $n=9$; day shift work $n=8$ ). Glucose tolerance and insulin sensitivity before and after 4 nights of shift work were measured by an intravenous glucose tolerance test and a hyperinsulinemic euglycemic clamp, respectively. Muscles biopsies were obtained to determine insulin signalling and mitochondrial function. Central and peripheral rhythmicity were assessed by measuring salivary melatonin and expression of circadian genes from hair samples, respectively.

Results: Fasting plasma glucose increased $\left(4.4 \pm 0.1\right.$ vs. $\left.4.6 \pm 0.1 \mathrm{mmol} \cdot \mathrm{L}^{-1} ; \mathrm{P}=0.001\right)$ and insulin sensitivity decreased $(25 \pm 7 \%, \mathrm{P}<0.05)$ following the night shift, with no changes following the day shift. Night shift work had no effect on skeletal muscle protein expression (PGC1 $\alpha$, UCP3, TFAM and mitochondria Complex II-V) or insulin-stimulated pAkt Ser473, pTBC1D4Ser318 and pTBC1D4Thr642. Importantly the metabolic changes after simulated night shifts occurred despite no changes in the timing of melatonin rhythmicity or hair follicle cell clock gene expression across the wake period (Per3, Perl, Nrldl and $\operatorname{Nrld2).}$

Conclusion: Only four days of simulated night shift work in healthy adults is sufficient to reduce insulin sensitivity which would be expected to increase the risk of T2D.

Key words: circadian rhythm, glucose, insulin, melatonin, mitochondria, shift work

Introduction

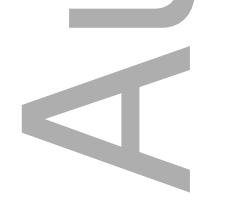

Exposure to shift work is common with more than $18 \%$ of the Australian workforce working outside the "normal" working hours of $0800 \mathrm{~h}$ to $1800 \mathrm{~h} .{ }^{1}$ Shift workers have more health problems even after controlling for lifestyle, body composition and socioeconomic status. ${ }^{2-4}$ Indeed, shift work increases all-cause This article is protected by copyright. All rights reserved 
mortality, ${ }^{5}$ and is an independent risk factor for insulin resistance, type 2 diabetes (T2D) and metabolic syndrome $e^{6}$.

Disruption to hormone and sleep rhythms, eating patterns and light exposure occur during shift work. Sleep is effected by shift work, ${ }^{7,8}$ due in part to the failure to shift the circadian rhythm of sleep to match the work schedule. However, it is unresolved whether the increased insulin resistance associated with shift work is due to changes in circadian rhythmicity per se and/or sleep patterns ${ }^{9}$ or to lifestyle changes that often accompany shift work, such as meal timing or food choices.

Shift work may also change metabolism through skeletal muscle mitochondrial disturbances. The production of reactive oxygen species (ROS) in mitochondria occurs in a circadian manner, ${ }^{10}$ and increases in skeletal muscle ROS production, ${ }^{11}$ and mitochondrial dysfunction are associated with insulin resistance. ${ }^{12}$ While a recent study investigated day-night rhythmicity in human skeletal muscle oxidative capacity ${ }^{13}$, to date the impact of shift work on skeletal muscle mitochondrial function and ROS production has not been directly investigated. In addition, muscle changes at mitochondrial level can also affect insulin sensitivity, but no previous study has examined the link between short term shift work and skeletal mitochondria and insulin sensitivity in healthy humans.

Therefore, we investigated the effect of four consecutive simulated night shifts on glucose homeostasis, mitochondrial function and central and peripheral rhythmicity compared with a simulated day shift schedule (Figure 1). To minimise potential confounding effects all the participants were provided with the same sleep opportunity (9 hours). Physical activity level was controlled before and during the study and participants maintained their habitual dietary preferences and intake during the study. To simulate travel to and from work, participants left the controlled conditions of the laboratory to walk in daylight for 30 minutes before and after each shift. This was expected to prevent changes in the phase of central circadian rhythms since our previous field study indicated no entrainment to 12 hour night shifts. ${ }^{14}$ In addition, participants used a driving simulator before and after each shift to simulate commuting and prepared their own normal meals. We hypothesised that such night shift work simulation would reduce whole body insulin sensitivity and skeletal muscle insulin signalling, reduce skeletal muscle mitochondrial respiration and increase mitochondrial ROS in the absence of either significant sleep debt or changes in rhythmicity or diet.

\section{Results}

This article is protected by copyright. All rights reserved 
There were no differences between the groups in age, gender balance, initial body weight, height, body mass index, screening Morningness/eveningness (MEQ) score, Melatonin Onset (MOn) or systolic and diastolic blood pressures (Table 1). Neither body weight nor the blood pressure changed across the study (Table 1).

\section{Fasting glucose, insulin and leptin}

Fasting blood glucose and insulin did not vary $(\mathrm{P}>0.05)$ with the day of testing (between the IVGTT or the HEC). Fasting glucose was unchanged after the day shift ( $4.6 \pm 0.2$ vs. $\left.4.5 \pm 0.1 \mathrm{mmol} \cdot \mathrm{L}^{-1} ; \mathrm{P}>0.05\right)$, but higher after the night shift $\left(4.4 \pm 0.1\right.$ vs. $\left.4.6 \pm 0.1 \mathrm{mmol} \cdot \mathrm{L}^{-1} ; \mathrm{P}=0.001\right)$. Fasting insulin was not affected by shift work (Figure 2). Plasma leptin levels obtained prior to the IVGTT did not change following either the day or night shifts (Supplementary Table 2).

\section{Intravenous Glucose Tolerance Test}

The glucose AUC was unchanged following the day shift $(\mathrm{P}>0.05)$ but increased $13.7 \%$ following the night shift ( $\mathrm{P}=0.008$; Figure 2). The insulin AUC was not different between the groups before shift work and did not change with shift work in either group (Figure 2).

\section{Hyperinsulinemic Euglycemic Clamp}

Paired data was only available from 5 day shift and 8 night shift participants. Three day shift participants and one night shift participant were excluded for different reasons. One day shift participant became unwell and vomited during the clamp, in another the target glucose level of $4.8-5.2 \mathrm{mmol} \mathrm{L}^{-1}$ during the clamp was not achieved, while the third was diagnosed with insulin resistance after analysis of insulin levels post study. For one night shift participant there were technical problems with the glucose analyser during the clamp. Pre-shift glucose infusion rate (GIR) was not different between the two groups (Figure 3, Supplementary Figure 1), however, it decreased following the night shift $(\mathrm{P}=0.005)$. Insulin sensitivity ( $\mathrm{M}$ value; Glucose infusion rate / insulin concentration during the last $30 \mathrm{~min})$ decreased following the night shift $(-25.6 \pm$ $7.4 \% ; \mathrm{P}=0.03)$ but not the day shift $(\mathrm{P}>0.05)$ (Figure 3$)$.

\section{Skeletal muscle insulin signalling}

Phosphorylated Akt Ser473, TBC1D4 Ser318 and TBC1D4 Thr642 during the HEC increased similarly in both groups before and after shift work (Figure 4).

\section{Skeletal muscle mitochondrial respiration}


Muscle protein expression of PGC1 $\alpha$, UCP3, TFAM and Complex II-V did not change in response to either the day or night shifts (Supplementary Table 3). There was no effect (P > 0.05) of day or night shifts on skeletal muscle mitochondrial respiration (Figure 5). Citrate synthase activity of skeletal muscle mitochondria also did not change in any group (Pre Day shift $5.88 \pm 0.61 \mu \mathrm{mol} \cdot \mathrm{min}^{-1} \mathrm{~g}^{-1} \mathrm{w} / \mathrm{w}$; Post Day shift $6.57 \pm 0.52 \mu \mathrm{mol} \cdot \mathrm{min} \cdot{ }^{-1} \mathrm{~g}^{-1} \mathrm{w} / \mathrm{w}$; Pre Night shift $6.86 \pm 0.51 \mu \mathrm{mol} \cdot \mathrm{min}^{-1} \mathrm{~g}^{-1} \mathrm{w} / \mathrm{w}$; Post Night shift 5.72 $\left.\pm 0.68 \mu \mathrm{mol} \cdot \mathrm{min}^{-1} \mathrm{~g}^{-1} \mathrm{w} / \mathrm{W}\right)$.

\section{Skeletal muscle mitochondrial $\operatorname{ROS}\left(\mathrm{H}_{2} \mathrm{O}_{2}\right)$ emission}

The data for 1 participant in each group was excluded from analysis for technical reasons with the respirometer (Day shift $\mathrm{n}=6$; Night shift, $\mathrm{n}=8$ ). Following night shifts, the ROS emission (per mg muscle wet-weight) was significantly reduced in Complex $\mathrm{I}+\mathrm{II}_{\text {Leak }}(\mathrm{P}=0.04$; Figure 5) with no other changes observed.

\section{Dietary intake}

There was no significant difference in dietary intake between the groups prior to entry into the study $(\mathrm{P}>$ 0.05, Figure 6). During the study, dietary energy, protein, total and saturated fat, available carbohydrates (starch and soluble sugars) and sugars during the shifts were similar in both groups (Figure 6). Those on night shift consumed more energy in the first meal opportunity during their "work period" at 2400h (2021 \pm $248 \mathrm{~kJ})$ than those on day shift at $1000 \mathrm{~h}(1349 \pm 90 \mathrm{~kJ})$ and this was reversed at the second "work period" meal opportunities for night shift participants at 0300h and day shift participants at 1300h (Supplementary Figure 2). With respect to macronutrients, protein intake was decreased in both groups during the study compared with pre-study $(\mathrm{P}=0.04)$ whereas other components did not change (Figure 6).

\section{Melatonin rhythms}

The onset of melatonin occurred after the last sample collection $(2200 \mathrm{~h})$ on the night before the trial commenced in 6/8 day shift participants and this pattern continued throughout the study. In the morning the Melatonin Offset (MOff) occurred around 0800h throughout the study (Supplementary Figures S4 \& S5, Supplementary Table 4). In the night shift group, the onset of melatonin occurred after 2200h in $6 / 9$ of the participants prior to commencement of the shifts. During the night shifts melatonin was secreted and the MOn was delayed by approximately 1.6 hours between day 3 and day $7(\mathrm{P}=0.02$; Supplementary Figures S4 \& S5). There were no changes in the MOff times across the study for the night shift participants or between the two shift schedules.

This article is protected by copyright. All rights reserved 


\section{Hair follicle cell gene expression}

The expression of Per3, Perl, Nrldl and Nrld2 mRNA decreased across the day ( $\mathrm{P}=0.001$; Supplementary Figure S5) similarly before (day 1) and after (day 7) the day shift and night shifts with no differences (P > $0.05)$ between the two shifts.

\section{Sleep}

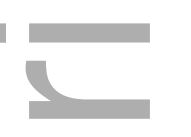

Subjective sleep duration prior to the shifts was similar for both groups (Supplementary Figure S6). During the simulated shifts there was a trend $(\mathrm{P}=0.06)$ for day shift $(7.1 \pm 0.6 \mathrm{~h})$ to sleep more than the night shift participants $(6.2 \pm 1.4 \mathrm{~h})$. When the nap prior to commencing the night shift was included, the night shift group obtained 1.6 hours less total sleep than the day shift group over the 4 days $(\mathrm{P}>0.05)$. Actigraph records (objective assessment) were only available for 3 day shift and 4 night shift participants due to technical difficulties. No difference in sleep duration, latency, percent sleep efficiency or wakefulness after sleep onset (WASO) was observed between the day and night shift participants (P > 0.05; Supplementary Figure S6, Supplementary Table 5).

\section{Discussion}

This study provides novel evidence showing that a roster of night shifts reduces glucose tolerance and insulin sensitivity in healthy non shift workers under controlled conditions. Importantly, this effect was observed despite no significant changes in the amount of sleep obtained or the diet in the day and the night shift participants. Thus, these results suggest that alterations in the times of wakefulness, eating and sleep per se may be sufficient for the previously observed decrease in insulin sensitivity in shift workers, independent of changes in circadian rhythm.

There have been few shift work simulation studies that were designed to eliminate or substantially reduce phase shifting as a variable that might explain the metabolic response. Al-Naimi, et al. assessed the postprandial glucose response to test meals at different times over a day shift and night shift. ${ }^{15}$ As expected, ${ }^{16}$ the timing of the melatonin rhythm and overall melatonin production were not affected by the sustained wakefulness during that study. However, a significant increase in plasma glucose was observed when participants stayed awake and ate food at night (night shift) compared with the day shift. This change in the glycaemia at night did not change the plasma insulin levels, but it is a clear marker of lower glucose tolerance. Another study by Morris et al. imposed 8 hour sleep opportunities between 2300h and 0700h 
(control/day shift) or between $1100 \mathrm{~h}$ and $1900 \mathrm{~h}$ (night shift) for 3 days. ${ }^{17}$ Peak melatonin levels in the night shift condition were 52\% and 59\% lower than the day shift condition on days 1 and 3 of the study, respectively. Moreover, the time of peak melatonin levels shifted by $1 \mathrm{~h} 19 \mathrm{~min}$ and $3 \mathrm{~h} 10 \mathrm{~min}$ on days 1 and 3 , respectively. ${ }^{17}$ In the current study peak melatonin levels were delayed, but more modestly, by approximately $1.6 \mathrm{~h}$ between day 3 and day 7 in the night shift group, however, unlike the Morris et al. study, we did not sample blood across 24 hours. Both studies found that simulated night shift impaired insulin sensitivity, even though Morris et al. used standard test meals to assess insulin sensitivity, while the current study used the gold standard hyperinsulinemic euglycemic clamp procedure. Interestingly, during the wake period the changes in insulin sensitivity were independent of changes in salivary melatonin onset, which is a marker of central rhythmicity or hair follicle cell clock gene mRNA expression which is a marker of peripheral central rhythmicity. In addition, the impairment of insulin sensitivity in the current study was not related to changes in the phosphorylation of the key insulin signalling proteins such as Akt, and TBC1D4. ${ }^{18-20}$ Taking all these results together, we suggest that the reduction in insulin sensitivity observed after the night shift work may have been due to insulin resistance in other tissues such as the liver. Further studies using glucose tracers during the hyperinsulinaemic euglycaemic clamp are needed to assess the insulin sensitivity of the liver after night shifts to answer these questions.

Mitochondrial function may also play a key role in insulin sensitivity, although whether mitochondrial dysfunction is a cause or consequence of insulin resistance remains controversial. ${ }^{12,21-25}$ Interestingly, while circadian misalignment induced by sleep deprivation in mice has been found to impair brain mitochondrial function, ${ }^{26}$ the impact of circadian misalignment on this in human skeletal muscle had not previously been examined. In the current study we measured skeletal muscle protein content and protein phosphorylation rather than gene expression as it provides a better indication of muscle function. To determine if any reduction in whole body insulin sensitivity was due, at least in part, to reductions in skeletal muscle insulin signalling we examined phosphorylation of Akt and TBC1D4 as markers of proximal and distal insulin signalling, respectively. PGC1 $\alpha$, which is a master regulator of mitochondrial biogenesis was measured in case there was a decrease in citrate synthase (CS) activity (an indicator of mitochondrial volume). The mitochondrial complexes were measured as a way, along with CS activity, to determine if there was a change in mitochondrial volume with night shift that may explain any changes in mitochondrial function. TFAM (mitochondrial transcription factor A) indicates nucleus-mitochondrial interactions that would be of interest if there was a change in CS activity of PGC1a. We also measured UCP3 as it is the main uncoupling protein in skeletal muscle with regards to understanding any changes in mitochondrial function. We found that four nights of shift work did not affect skeletal muscle mitochondrial respiration, mitochondrial content 
based on CS activity or protein expression of PGC1 1 , TFAM and mitochondrial complexes. Our findings therefore indicate that the decreased insulin sensitivity after night shifts was not due to changes in mitochondrial respiration, volume or biogenesis. On the other hand, an intriguing finding of this study was the decrease in mitochondrial $\operatorname{ROS}\left(\mathrm{H}_{2} \mathrm{O}_{2}\right)$ emission in the $\mathrm{CI}+\mathrm{II}_{\text {Leak }}$ state following night shifts. Currently, it is not possible to explain the reason of these intriguing results, but in contrast to the previous literature, recent evidence has shown that physiological levels of ROS generation are required for normal insulin responses ${ }^{27}$. This question needs to be investigated more carefully in future studies, particularly in the context of chronic shift workers.

It has been proposed that predominant or additional drivers of poor metabolic health of shift workers may be poor nutrition and in particular altered appetite, increased total energy intake, ${ }^{28}$ or increased fat and snack intake. $^{29}$ Previous shift work simulation studies have imposed strict dietary control on the participants which could in itself alter metabolic function. ${ }^{30}$ We provided the participants with individualised ingredients to prepare their own normal meals and snacks in an attempt to make the simulation as close to a real work situation as possible. An interesting consequence of this approach was that day shift participants voluntarily had only a small snack on the first meal opportunity (1030h-1100h), whereas for the night shift participants this small meal occurred in the second meal opportunity during their shift (0300h to 0330h). To what extent this may have contributed to the change in insulin sensitivity observed in this study is not known. The dietary intake of protein was slightly lower during both day and night shifts compared with pre-study levels, but there was no difference in intake of any macronutrients between the day and night shifts. This would suggest that the decrease in insulin sensitivity we report here in the night shift group was not due to altered energy or fat intake.

Participants on night shift slept only an average of 25 minutes less per $24 \mathrm{~h}$ period than the day shift participants which totalled $1.6 \mathrm{~h}$ across the whole 4-day period (not statistically significant). This is less than we have observed in the field, where the total sleep obtained on night shifts was 1.7 hours less per night than the 7.4 hours of sleep obtained on days off. ${ }^{8}$ In a simulation study similar to that used in the current study, the cumulative sleep debt accrued over 4 night shifts was modest at approximately 2.5 hours. ${ }^{31}$ This would suggest that although the actigraphic analysis in current study lacked power, sleep debt is unlikely to have had a major impact on glucose metabolism.

Despite the novel aspects of this study, the study had some limitations. For instance, the sample size was relatively small, in part due to the challenging nature of the study which required participants undertaking This article is protected by copyright. All rights reserved 
invasive procedures such as several venous cannulations and muscle biopsies while living under controlled conditions in our research facility. While the repeated measures analysis indicated a robust change in insulin sensitivity in the night shift group across the study, but not the day shift group, the study lacked the power to detect a statistically significant change in insulin sensitivity between the day shift and night shift work participants after simulated shift work. In addition, several technical problems meant that the full data set was not available from some of the participants. We chose to use a non-randomised and non-cross over design in order to match the two groups in terms of gender, age, physical activity levels and BMI, and to reduce the number of cannulations and muscle biopsies in each participant, respectively. Our determination of central and peripheral clocks was based on only partial profiles of salivary melatonin and hair follicle gene expression, respectively. This was because as we decided to not collect samples during the participants sleep time, so as to avoid any disturbance on the sleep, which could affect the participant's metabolic responses. Therefore, we do not know for certain that no changes occurred in central and/or peripheral clocks following the night shift. However, despite these limitations, the study was able to demonstrate a significant reduction in insulin sensitivity in the night shift group, with all participants (8/8) being lower after the simulated night shift.

In conclusion, a 4 day roster of simulated night shift work is sufficient to reduce insulin sensitivity by approximately $25 \%$, independent of diet or changes in circadian rhythmicity. These results have important implications for chronic shift workers who not only have changes in their work cycles but also tend to sleep less and have unbalance diets, both of which can reduce insulin sensitivity. Our results provide important mechanistic understanding of the negative effects of shift work on glucose metabolism and insulin action that result in increased rates of T2D in chronic shift workers.

\section{Materials and methods}

\section{Participants}

Seventeen healthy non-smokers ( 9 females, 8 males; age $25.6 \pm 5.1$ years; Mean \pm SD) subjects completed this study in an environmentally controlled facility within Victoria University (Melbourne, Australia). Participants were eligible to take part in the study if they had intermediate morningness/eveningness chronotype scores, ${ }^{32}$ and an intermediate melatonin onset measurement (assessed between 1800h and 2200h) collected under a light intensity of $<50$ lux. Participants completed physical activity (7 days) and dietary records (4 days) before entering the study and during the study. In addition, during the study the heart rate of the participants was recorded during the awake period (data not shown). Participants were also provided with all food and drinks during the study in agreement with the information provided in the dietary 
records as well as the participants' personal preferences. Participants were excluded from participation if they had diabetes, currently smoked, were taking any medications affecting muscle or liver metabolism, exhibited disturbed sleep patterns, performed more than 1 hour of exercise per day, were current shift workers or who had travelled overseas within the last 2 months. Participants were assigned to either a simulated day shift group or a simulated night shift group, balanced for age, body weight, height, gender and physical activity. After an explanation of the experimental procedures all participants gave their written informed consent before commencing the study which was approved by the Human Ethics Committees of Victoria University and the University of Adelaide (Australia).

\section{Experimental protocol}

The study was conducted in an environmentally controlled facility within the Institute of Sport, Exercise and Active Living (ISEAL) at Victoria University. On four consecutive days the control day shift group were assigned to have a 9 hour sleep opportunity between $2200 \mathrm{~h}$ and $0700 \mathrm{~h}$, while the night shift group was assigned a 9 hour sleep opportunity between 0800h and 1700h (Figure 1). When two participants were studied simultaneously, they were allocated to separate rooms and were assigned to the same shift. Participants recorded their dietary intake for 4 days before entering the laboratory using a semi-quantitative 4-day weighed food diary and were provided with food and beverages similar to this throughout the study since changing the diet can have its own effects on insulin sensitivity.

The study was completed in 2 stages with an intervening break for operational reasons.

Stage 1: After arriving at the research facility, the participants prepared their dinner at $2000 \mathrm{~h}$ and then were confined to their bed in a completely darkened room from $2200 \mathrm{~h}$ until $0700 \mathrm{~h}$ to sleep. Then, after an overnight fast, an intravenous glucose tolerance test (IVGTT, see below) commenced at $\sim 0830 \mathrm{~h}$. Participants stayed for the rest of the day in the research facility. A meal opportunity was provided after the IVGTT ( 12:30h) and again at 1730h and 2000h. Participants could leave the facility for 30 min each day $(1730 \mathrm{~h}-1800 \mathrm{~h})$ and were able to undertake low to moderate intensity walking, but not exercise training. Participant heart rates were recorded during the awake period (data not shown). Saliva was collected at $1800 \mathrm{~h}, 1900 \mathrm{~h}, 2000 \mathrm{~h}, 2100 \mathrm{~h}$ and $2200 \mathrm{~h}$, after which participants were confined to their bedrooms to sleep. The next morning (Day 2) after an overnight fast, muscle biopsies (see below) were collected before and after a hyperinsulinaemic euglycaemic clamp (HEC, see below). All participants performed the tests at the same time of day $( \pm 1 \mathrm{~h})$. Upon completing the second biopsy, the participants were free to leave the research facility.

This article is protected by copyright. All rights reserved 
Stage 2: This stage began $2.6 \pm 1.2$ days and $1.8 \pm 0.5$ days after Stage 1 for the day shift and night shift participants, respectively. Participants returned to the facility at approximately $1400 \mathrm{~h}$ and those assigned to the night shift were given a nap opportunity between $1500 \mathrm{~h}$ and $1800 \mathrm{~h}$. Hourly saliva sampling commenced at $1800 \mathrm{~h}$, with those on the day shift ceasing sampling at $2200 \mathrm{~h}$ and recommencing sampling at $0700 \mathrm{~h}$, 0800h and 0900h. Those on the night shift continued hourly saliva collection until the commencement of their sleep opportunity at $0800 \mathrm{~h}$. The maximum light intensity recorded in the night shift was 290 lux. Participants spent their time in the facility completing questionnaires, using a driving simulator, watching TV, playing games, reading, studying or cooking. All these activities kept them active, however, they were not permitted to engage in any formal exercise. The day shift group maintained their sleep opportunity between $2200 \mathrm{~h}$ and $0700 \mathrm{~h}$ throughout the study. The night shift participants had 3 consecutive days of sleep opportunity between $0800 \mathrm{~h}$ and $1700 \mathrm{~h}$, followed by a transition sleep opportunity from $0800 \mathrm{~h}$ to $1500 \mathrm{~h}$ on Day 6 during the last 2 days of the stage 2 (Day 7 and 8) to help them return to night sleep (2200h to 0700h). On Day 7 and Day 8 after an overnight fast, both groups were subjected to the IVGTT and muscle biopsies/HEC as above (Figure 1). To simulate commuting to work, during stage 2 participants left the facility and were encouraged to walk outside (but not engage in moderate or high intensity exercise) for 30 min between $0800 \mathrm{~h}-0830 \mathrm{~h}$ and $0700 \mathrm{~h}-0730 \mathrm{~h}$ for the day shift and night shift groups, respectively and again in the afternoon between $1730 \mathrm{~h}-1800 \mathrm{~h}$ for both groups. Adherence to these activity restrictions were monitored with a heart rate monitor. Both groups were assigned five eating opportunities. For the day shift these were $0730 \mathrm{~h}-0800 \mathrm{~h}, 1030 \mathrm{~h}-1100 \mathrm{~h}, 1300 \mathrm{~h}-1400 \mathrm{~h}, 1730 \mathrm{~h}-1800 \mathrm{~h}$ and $2000 \mathrm{~h}-2100 \mathrm{~h}$. For the night shift they were $1700 \mathrm{~h}-1730 \mathrm{~h}, 2000 \mathrm{~h}-2100 \mathrm{~h}, 2400 \mathrm{~h}-0030 \mathrm{~h}, 0300 \mathrm{~h}-0330 \mathrm{~h}$ an $0600 \mathrm{~h}-0700 \mathrm{~h}$. No food or beverages (except water) were allowed outside of these times. No caffeinated beverages were allowed.

\section{Specific methods}

Intravenous glucose tolerance test (IVGTT): Teflon catheters $(20 \mathrm{G})$ were inserted into an antecubital vein of both arms. A bolus dose of $0.3 \mathrm{~g} \cdot \mathrm{kg}^{-1}$ of glucose $(25 \%$ dextrose solution in saline, Baxter Healthcare Corporation, Toongabbie, NSW, Australia) was injected into a vein. Then, blood ( $3 \mathrm{ml})$ was collected from the contralateral vein into fluoride/potassium oxalate and lithium heparin tubes 20, 10 and 1 min before and $2,3,4,5,6,8,10,12,14,16,19,22,25,30,40,50,60,70,80,90,100,110,120,140,160$ and $180 \mathrm{~min}$ after the bolus. Whole blood glucose was analysed using a glucose analyser (YSI 2300 Stat, Yellow Springs Instrument, Yellow Springs). Heparinised blood was centrifuged and plasma stored at $-80 \mathrm{C}$ for subsequent insulin analysis.

This article is protected by copyright. All rights reserved 
Hyperinsulinaemic euglycaemic clamp (HEC): A $20 \mathrm{G}$ Teflon catheter was inserted into antecubital vein on each arm. The arm to be used for blood collection was placed within an electrical heated cylinder, for arterialization of the venous blood. Five minutes after administration of a bolus dose of insulin $\left(9 \mathrm{mU} \cdot \mathrm{kg}^{-1}\right.$; Actrapid; Novo Nordisk, Bagsvaerd, Denmark), insulin was infused at a rate of $40 \mathrm{mU} \cdot \mathrm{m}^{2} \cdot$ body surface area $\min ^{-1}$ together with $25 \% \mathrm{D}$-glucose for $115 \mathrm{~min}$. Blood was collected every 5 minutes from the contralateral vein, assayed for glucose and the infusion rate adjusted accordingly to maintain blood glucose levels between 4.8 and $5.2 \mathrm{mM}$. The steady state glucose infusion rate (GIR) was calculated as the average over the last $30 \mathrm{~min}$ of the clamp and expressed as $\mathrm{mg} \cdot \mathrm{kg} \cdot \mathrm{min}^{-1}$. Blood samples collected before the start of the HEC and at 30, 60, 90 and 120 min of the HEC were assayed for plasma insulin.

Muscle biopsies: Vastus lateralis muscle biopsies (approximately $150 \mathrm{mg}$ ) were obtained by a qualified medical doctor before and immediately after each HEC from separate incisions separated by $\sim 1 \mathrm{~cm}$. The site of the biopsies was anesthetised using lignocaine without epinephrine. Samples were used to assess mitochondrial respiration on fresh tissue and the rest snap frozen in liquid nitrogen and then stored at $-80 \mathrm{C}$.

Western blot analysis: Protein (4-6 $\mu \mathrm{g}$ per well) along with a 4 point calibration curve was separated by gel electrophoresis at 150V for $75 \mathrm{~min}$ for OXPHOS proteins on 4-20\% Criterion Stain-Free precast gels (Bio$\mathrm{Rad}$ ) and for all other proteins $200 \mathrm{~V}$ for $45 \mathrm{~min}$ with $4-15 \%$ or $7.5 \%$ Criterion Stain-Free precast gels (BioRad). Gels were UV activated for total protein visualisation on the membrane after transfer by ChemiDocTM MP Imaging System (Bio-Rad). The membrane was blocked with $5 \%$ (w/v) skim milk powder dissolved in Tris-buffered saline containing 0.1\% Tween-20 (TBST) at room temperature for $1 \mathrm{~h}$. The primary antibodies described below were diluted in 5\% (w/v) BSA and 0.1\% Sodium Azide in TBST or blocking buffer and incubated overnight at $4^{\circ} \mathrm{C}$. The next day following a 1 hour incubation with anti-mouse or anti-rabbit HRP-secondary antibodies and a series of washes in TBST, chemiluminescent signal was developed (SuperSignal West Femto, Pierce) and imaged by the ChemiDocTM MP Imaging System (Bio$\mathrm{Rad})$.

Mitochondria respirometry: Skeletal muscle fibres were permeabilised after collection by agitation with saponin $(0.005 \% \mathrm{wt} / \mathrm{vol})$ for $30 \mathrm{~min}$ at $4^{\circ} \mathrm{C}$, then washed in respiratory buffer (MiR05) for respiration analysis. Tissue (2-3 mg) was added in duplicate to each chamber of a high-resolution respirometer (Oroboros Oxygraph-2K; Oroboros Instruments, Austria) containing MiR05 at $37^{\circ} \mathrm{C}$. Oxygen flux (leak) was assessed by adding malate (final concentration $2 \mathrm{mM})$ and pyruvate $(10 \mathrm{mM})$ for complex $\mathrm{I}\left(\mathrm{CI}_{\text {Leak }}\right)$ and succinate $(10 \mathrm{mM})$ for complex $\mathrm{I}+\mathrm{II}$ in the absence of ADP $\left(\mathrm{CI}+\mathrm{II}_{\text {Leak }}\right)$. Maximal oxidative phosphorylation 
(OXPHOS) was quantified by the addition of ADP $(5 \mathrm{mM})$. Then, cytochrome $c(10 \mathrm{mM})$ was added to assess for possible outer mitochondrial membrane defect (10\% increase in flux rate). Subsequently, carbonylcyanide-4-(trifluoromethoxy)-phenyl-hydrazone was titrated (0.5 $\mu \mathrm{M}$ steps) to achieve maximum flux through the electron transfer system $\left(\mathrm{CI}+\mathrm{CII}_{\mathrm{ETS}}\right)$. Finally, electron transport through complex I and III was inhibited by the sequential addition of rotenone $(1 \mu \mathrm{M})$ and antimycin $\mathrm{A}(5 \mu \mathrm{M})$, respectively.

Mitochondrial hydrogen peroxide $\left(\mathrm{H}_{2} \mathrm{O}_{2}\right)$ emission: $\mathrm{H}_{2} \mathrm{O}_{2}$ emission was measured simultaneously with mitochondrial respiration in each chamber via the reaction with Amplex UltraRed (5 $\mu \mathrm{M}$; Life Technologies), horseradish peroxidase $\left(10 \mathrm{U} \cdot \mathrm{ml}^{-1}\right)$ and superoxide dismutase $\left(5 \mathrm{U} \cdot \mathrm{ml}^{-1}\right)$ at $37^{\circ} \mathrm{C}$. The rate of fluorescent product appearance was monitored using fluorospectrometers (O2k-Fluo LED2-Module, Oroboros Instruments, Austria).

Citrate synthase activity: Skeletal muscle tissue (15 - $20 \mathrm{mg})$ was placed in $300 \mu \mathrm{L}$ buffer $(175 \mathrm{mM} \mathrm{KCl}$ and $2 \mathrm{mM}$ EDTA, pH 7.4), mechanically homogenized for $30 \mathrm{~s}$ at $30 \mathrm{~Hz}$ (TissueLyser, Qiagen, Hilden, Germany), freeze-thawed three times, then centrifuged at $4^{\circ} \mathrm{C}$. Supernatant $(5 \mu \mathrm{L})$ was loaded in a $96-$ well plate in duplicate in order to measure the citrate synthase activity spectrophotometrically at $412 \mathrm{~nm}$ and $37^{\circ} \mathrm{C}$ (iMark, Bio-Rad).

Dietary intake: Dietary records were used to provide the subjects with similar food and drinks during the study. Additionally, participants provided semi-quantitative food diaries during the study that were analysed using a computerised database (Foodworks 7 Professional Edition, Xyris Software, Australia).

Saliva melatonin: To examine central circadian rhythmicity, saliva was collected using Salivettes (Sarstedt Australia, Technology Park, South Australia) and melatonin analyses were performed by radioimmunoassay 33 (Buhlmann Laboratories, Allschwil, Switzerland). Onset of melatonin secretion (MOn) was defined as the time of day that the melatonin concentration exceeded $10 \mathrm{pM}$. In cases where the levels had not exceeded 10 pM by the time sampling ceased, the onset was recorded as occurring 1 hour later than the last sample collection. Similarly, for determining the offset time (MOff), this was the time that the melatonin decreased below $10 \mathrm{pM}$; if it was already below $10 \mathrm{pM}$ before the first sample of the morning it was deemed to have occurred 1 hour earlier than that time

Hair follicle cell mRNA: Hair samples ( 20) obtained from different regions of the scalp at 0800h, 1200h, $1600 \mathrm{~h}$ and $2000 \mathrm{~h}$ on day 1 and 7 were placed into tubes containing $100 \mu \mathrm{l}$ of lysis buffer and stored at This article is protected by copyright. All rights reserved 
$80^{\circ} \mathrm{C}^{34}$ The RNA was extracted and DNAs treated using RNAqueous Micro Kits (Life Technologies Australia, Mulgrave, Victoria). RNA was reverse transcribed to cDNA using Turbo Superscript III (Life Technologies), random hexamers (Geneworks, Thebarton, SA) and DNTPs (GE Healthcare, North Sydney, NSW). Gene expression was quantified using Power Sybr Green master mix and a 7500 Real Time PCR System (Life Technologies). All primers used (Supplementary Table 1) were sourced from GeneWorks. Analysis of $N r 1 d 1, N r 1 d 2$, Perl and Per3 $m R N A$ expression was normalised to the expression of $\beta$-actin using the $-\Delta \Delta \mathrm{Ct}$ method. ${ }^{35}$

Sleep: Participants wore an Actiwatch activity monitor (Phillips Respironics, Bend, OR) over the 4-7 days before the experimental period to ensure the required sleep schedule was maintained, and during the study. However, due to equipment failure, objective sleep information was available for only 7 of the 17 participants (3 day shift and 4 night shift). Each participant, however, provided in a sleep diary the estimated time of sleep onset and wake up times, from which subjective sleep duration was calculated.

Hormone analysis: Plasma insulin was analysed by double antibody RIA (HI-14K, EMD Millipore, Billerica, Massachusetts, USA). Plasma leptin was analysed in baseline samples for the IVGTT and HEC by double antibody RIA (HL-81K, EMD Millipore).

\section{Statistical Analysis}

Area under the glucose and insulin curves during the IVGTT was calculated using GraphPad Prism 7. All data were analyzed by repeated measures 2-way ANOVA (IBM SPSS Statistics Version 20). When the ANOVA revealed a significant interaction specific differences were identified using a least significant difference post hoc test. Percentage change between pre- and post- shift periods for the day and night shift groups were compared using paired samples t-tests. Actigraphic sleep data was first analysed using Phillips Respironics Actiware software (version 6.0) and then repeated measures ANOVA across the 3 day lead in and the 4 days of simulated day or night shifts. Friedman's non-parametric analysis of variance was used to determine if the time of onset varied within the groups across the duration of the study. Friedman's nonparametric analysis of variance was used to determine if the time of onset varied within the groups across the duration of the study. Data are presented as means \pm SEM. A P value of $\leq 0.05$ was considered significant.

\section{Acknowledgments}

This article is protected by copyright. All rights reserved 
The authors would like to thank the participants for taking part in this study and G. Kaur, M. Konjarski, L. Rattanatray, M. Salkeld and R. Thomson for technical assistance. This work was supported by a grant from the National Health and Medical Research Council of Australia (Grant \#1029869 to D.J.K., G.K.M. and J.A.O.). I.L was supported by Future Leader Fellowship (ID: 100040) from the National Heart Foundation of Australia. D.J.K takes full responsibility for the work as a whole, including the study design, access to data, and the decision to submit and publish the manuscript.

\section{Author contributions}

D.J.K., J.A.O., G.K.M., R.B., M.J.B. and M.L.J. designed research;

R.B., E.C.M., I.L., A.G., F.F., F.C., M.J.B. and G.K.M. performed the research;

D.J.K., M.J.B., G.K.M., R.B., I.L., A.J.T., D.S.H. and M.L.J. analyzed data and interpretation;

D.J.K, G.K.M and R.B. wrote the paper.

\section{Conflict of interest}

The authors declare no conflict of interest

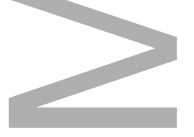

\section{References}

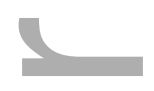

1 Australian_Bureau_of_Statistics: Australian Labour Market Statistics, Oct 2010.wwwabsgovau 6105.0: 2010.

2 Zimberg IZ, Fernandes Junior SA, Crispim CA, Tufik S, de Mello MT: Metabolic impact of shift work. Work 41 Suppl 1: 4376-83, 2012.

3 Banks S, Dorrian J, Grant C, Coates A 2015. Circadian misalignment and metabolic consequences: Shiftwork and altered meal times. In: Watson RR (Ed.) Modulation of Sleep by Obesity, Diabetes, Age, and Diet. San Diego, Academic Press.

This article is protected by copyright. All rights reserved 
Antunes LC, Levandovski R, Dantas G, Caumo W, Hidalgo MP: Obesity and shift work: chronobiological aspects. Nutr Res Rev 23: 155-68, 2010.

Gu F, Han J, Laden F, Pan A, Caporaso NE, Stampfer MJ, Kawachi I, Rexrode KM, Willett WC, Hankinson SE, Speizer FE, Schernhammer ES: Total and cause-specific mortality of U.S. nurses working rotating night shifts. Am J Prev Med 48: 241-52, 2015.

De Bacquer D, Van Risseghem M, Clays E, Kittel F, De Backer G, Braeckman L: Rotating shift work and the metabolic syndrome: a prospective study. Int J Epidemiol 38: 848-54, 2009.

7 Akerstedt T, Wright KP, Jr.: Sleep loss and fatigue in shift work and shift work disorder. Sleep Med Clin 4: 257-271, 2009.

Ferguson SA, Baker AA, Lamond N, Kennaway DJ, Dawson D: Sleep in a live-in mining operation: The influence of start times and restricted non-work activities. Appl Ergon 42: 71-5, 2010.

9 Leproult R, Holmbäck U, Van Cauter E: Circadian misalignment augments markers of insulin resistance and inflammation, independently of sleep loss. Diabetes 63: 1860-1869, 2014.

Langmesser S, Albrecht U: Life time_circadian clocks, mitochondria and metabolism. Chronobiol Int 23: 151-157, 2006.

11 Anderson EJ, Lustig ME, Boyle KE, Woodlief TL, Kane DA, Lin C-T, Price JW, III, Kang L, Rabinovitch PS, Szeto HH, Houmard JA, Cortright RN, Wasserman DH, Neufer PD: Mitochondrial $\mathrm{H} 2 \mathrm{O} 2$ emission and cellular redox state link excess fat intake to insulin resistance in both rodents and humans. J Clin Invest 119: 573-581, 2009.

12 Montgomery MK, Turner N: Mitochondrial dysfunction and insulin resistance: an update. Endocr Connect 4: R1-R15, 2015.

13 van Moorsel D, Hansen J, Havekes B, Scheer FAJL, Jörgensen JA, Hoeks J, Schrauwen-Hinderling VB, Duez H, Lefebvre P, Schaper NC, Hesselink MKC, Staels B, Schrauwen P: Demonstration of a day-night rhythm in human skeletal muscle oxidative capacity. Mol Metab 5: 635-645, 2016.

14 Ferguson SA, Kennaway DJ, Baker A, Lamond N, Dawson D: Sleep and circadian rhythms in mining operators: Limited evidence of adaptation to night shifts. Appl Ergon 43: 695-701, 2012.

This article is protected by copyright. All rights reserved 
15 Al-Naimi S, Hampton SM, Richard P, Tzung C, Morgan LM: Postprandial metabolic profiles following meals and snacks eaten during simulated night and day shift work. Chronobiol Int 21: 937 947, 2004.

16 Zeitzer JM, Duffy JF, Lockley SW, Dijk DJ, Czeisler CA: Plasma melatonin rhythms in young and older humans during sleep, sleep deprivation, and wake. Sleep 30: 1437-43, 2007.

17 Morris CJ, Yang JN, Garcia JI, Myers S, Bozzi I, Wang W, Buxton OM, Shea SA, Scheer FAJL: Endogenous circadian system and circadian misalignment impact glucose tolerance via separate mechanisms in humans. Proc Natl Acad Sci USA 112: E2225-E2234, 2015.

18 Treebak JT, Pehmoller C, Kristensen JM, Kjobsted R, Birk JB, Schjerling P, Richter EA, Goodyear LJ, Wojtaszewski JF: Acute exercise and physiological insulin induce distinct phosphorylation signatures on TBC1D1 and TBC1D4 proteins in human skeletal muscle. J Physiol 592: 351-75, 2014.

19 Funai K, Schweitzer GG, Sharma N, Kanzaki M, Cartee GD: Increased AS160 phosphorylation, but not TBC1D1 phosphorylation, with increased postexercise insulin sensitivity in rat skeletal muscle. Am J Physiol Endocrinol Metab 297: E242-51, 2009.

20 Wojtaszewski JF, Hansen BF, Gade, Kiens B, Markuns JF, Goodyear LJ, Richter EA: Insulin signaling and insulin sensitivity after exercise in human skeletal muscle. Diabetes 49: 325-31, 2000.

21 Bandyopadhyay GK, Yu JG, Ofrecio J, Olefsky JM: Increased malonyl-CoA levels in muscle from obese and type 2 diabetic subjects lead to decreased fatty acid oxidation and increased lipogenesis; thiazolidinedione treatment reverses these defects. Diabetes 55: 2277-85, 2006.

22 Holloway GP, Thrush AB, Heigenhauser GJ, Tandon NN, Dyck DJ, Bonen A, Spriet LL: Skeletal muscle mitochondrial FAT/CD36 content and palmitate oxidation are not decreased in obese women. Am J Physiol Endocrinol Metab 292: E1782-9, 2007.

23 Trenell MI, Hollingsworth KG, Lim EL, Taylor R: Increased daily walking improves lipid oxidation without changes in mitochondrial function in type 2 diabetes. Diabetes Care 31: 1644-9, 2008.

24 van Tienen FH, Praet SF, de Feyter HM, van den Broek NM, Lindsey PJ, Schoonderwoerd KG, de Coo IF, Nicolay K, Prompers JJ, Smeets HJ, van Loon LJ: Physical activity is the key determinant of This article is protected by copyright. All rights reserved 
skeletal muscle mitochondrial function in type 2 diabetes. J Clin Endocrinol Metab 97: 3261-9, 2012.

Fabbri E, Chia CW, Spencer RG, Fishbein KW, Reiter DA, Cameron D, Zane AC, Moore ZA, Gonzalez-Freire M, Zoli M, Studenski SA, Kalyani RR, Egan JM, Ferrucci L: Insulin Resistance Is Associated With Reduced Mitochondrial Oxidative Capacity Measured by 31P-Magnetic Resonance Spectroscopy in Participants Without Diabetes From the Baltimore Longitudinal Study of Aging. Diabetes 66: 170-176, 2017.

26 Andreazza AC, Andersen ML, Alvarenga TA, de-Oliveira MR, Armani F, Ruiz FS, Giglio L, Moreira JC, Kapczinski F, Tufik S: Impairment of the mitochondrial electron transport chain due to sleep deprivation in mice. J Psychiatr Res 44: 775-80, 2010.

27 Loh K, Deng H, Fukushima A, Cai X, Boivin B, Galic S, Bruce C, Shields BJ, Skiba B, Ooms LM, Stepto N, Wu B, Mitchell CA, Tonks NK, Watt MJ, Febbraio MA, Crack PJ, Andrikopoulos S, Tiganis T: Reactive oxygen species enhance insulin sensitivity. Cell Metab 10: 260-272, 2009.

Lowden A, Moreno C, Holmback U, Lennernas M, Tucker P: Eating and shift work - effects on habits, metabolism and performance. Scand J Work Environ Health 36: 150-62, 2010.

29 Cain SW, Filtness AJ, Phillips CL, Anderson C: Enhanced preference for high-fat foods following a simulated night shift. Scand J Work Environ Health 41: 288-93, 2015.

30 Buxton OM, Pavlova M, Reid EW, Wang W, Simonson DC, Adler GK: Sleep restriction for 1 week reduces insulin sensitivity in healthy men. Diabetes 59: 2126-2133, 2010.

31 Lamond N, Dorrian J, Roach GD, McCulloch K, Holmes AL, Burgess HJ, Fletcher A, Dawson D: The impact of a week of simulated night work on sleep, circadian phase, and performance. Occup Environ Med 60: e13, 2003.

32 Horne JA, Ostberg O: A self-assessment questionnaire to determine morningness-eveningness in human circadian rhythms. Int J Chronobiol 4: 97-110, 1976.

33 Voultsios A, Kennaway DJ, Dawson D: Salivary melatonin as a circadian phase marker: Validation and comparison with plasma melatonin. J Biol Rhythms 12: 457-466, 1997. 
Akashi M, Soma H, Yamamoto T, Tsugitomi A, Yamashita S, Yamamoto T, Nishida E, Yasuda A, Liao JK, Node K: Noninvasive method for assessing the human circadian clock using hair follicle cells. Proc Natl Acad Sci USA 107: 15643-15648, 2010.

Livak KJ, Schmittgen TD: Analysis of relative gene expression data using real-time quantitative PCR and the 2(-Delta Delta C(T)) Method. Methods 25: 402-8, 2001.

\section{Legends to figures}

Figure 1. Schematic of the trial design for the day shift (left panel) and night shift participants (right panel). The black bars indicate the times of the sleep opportunities. The vertical hashed bars indicate the times of day when the participants were permitted to briefly leave the facility, to simulate a commute to and from work. The gap between stage 1 and stage 2 ranged from $2.6 \pm 1.2$ days and $1.8 \pm 0.5$ days for the day shift and night shift participants, respectively. IVGTT $=$ Intravenous glucose tolerance test. HEC $=$ hyperinsulinemic euglycemic clamp (muscle biopsies were obtained before the commencement and immediately before the end of each HEC). A indicates the approximate time of arrival at the facility, L indicates when they left the facility and $\mathrm{M}$ indicates the meal and snack opportunities.

Figure 2. Glucose tolerance of the subjects in the night shift protocol was significantly impaired compared to the subjects in the day shift protocol. Blood glucose $\left(\mathrm{mmol} \cdot \mathrm{L}^{-1}\right)$ and plasma insulin $\left(\mu \mathrm{U} \cdot \mathrm{ml}^{-1}\right)$ measured before and after a bolus injection of glucose $\left(0.3 \mathrm{~g} \cdot \mathrm{kg}^{-1}\right)$ into participants $(\mathrm{a}, \mathrm{c})$ before $(\mathbf{O})$ and after $(\mathbf{O})$ the day shift (mean \pm SEM; $N=7)$ and $(b, d)$ before $(O)$ and after $(O)$ the night shift $(N=9)$ and the percentage change (mean \pm SEM) in the glucose (e) and insulin (f) AUC for the day (O) and night (O) shift participants. Data were compared by 2-way repeated measures ANOVA. Note that some SEM bars are obscured by the symbols. $* \mathrm{P}<0.05$ versus Day shift.

Figure 3. Insulin sensitivity significantly decreased in the subjects following the night shift protocol while no changes were observed in the day shift subjects. The (a) glucose infusion rate and (b) insulin sensitivity (M value, glucose infusion rate divided by the insulin concentration) measured during the last 30 minutes of the hyperinsulinaemic euglycaemic clamps determined pre- and post- shift work for the day shift $(\mathrm{N}=5)$ and night shift $(\mathrm{N}=8)$. Data were compared by a paired sample t-test. The data are the mean $\pm \mathrm{SEM}$. $* \mathrm{P}<0.05$ vs Pre (paired t test).

This article is protected by copyright. All rights reserved 
Figure 4. The night shift protocol did not induce changes in insulin signal transduction proteins in skeletal muscle. Representative blots and Western blot analysis of pAkt Ser473, pTBC1D4 Ser318 and pTBC1D4 Thr642 protein relative to total Akt2 and TBC1D4 from biopsies obtained at the start (B; Basal) and end (I; Insulin) of the hyperinsulinemic euglycemic clamp, before and after participants had completed their day shift or night shifts. Data are the mean \pm SEM for 5 day shift and 7 night shift participants. * indicates main effect for insulin, $\mathrm{P}<0.05$.

Figure 5. Skeletal muscle mitochondrial respiration (a) did not differ in the night and day shift groups before and after each protocol, but subjects in the night shift group showed a significant reduction in the emission of Reactive Oxygen Species (ROS) in Complex $\mathrm{I}+\mathrm{II}_{\text {Leak }}$ after 4 days of night shift. $\mathrm{H}_{2} \mathrm{O}_{2}$ emission (b) from skeletal muscle biopsies from participants before $(\square)$ and after $(\boldsymbol{\square})$ the day shifts, and before ( $\square$ ) and after $(\square)$ the night shifts. Measurements were made during state-4 (Leak), ADP stimulated state-3 oxidative phosphorylation (OXPHOS) and FCCP induced uncoupled (ETS) respiration, which was supported by pyruvate+malate (CI) and succinate (CII) oxidation; rotenone was added for $\mathrm{CII}_{\mathrm{ETS}}$. The $\mathrm{O}_{2}$ flux data are mean \pm SEM (pmol.s $\cdot \mathrm{mg}^{-1}$ wet weight; $\mathrm{N}=7$ day and 9 night shift participants). $\mathrm{H}_{2} \mathrm{O}_{2}$ flux data are mean \pm SEM (pmol. $\cdot \mathrm{mg}^{-1}$ wet weight; $\mathrm{N}=6$ day and 8 night shift participants). Data were compared by 2 -way repeated measures ANOVA. * $\mathrm{P}<0.05$ vs Pre night shift.

Figure 6. Dietary energy intake and total fat and carbohydrate consumption did not differ between groups before and after the night and day shifts, respectively. However, subjects in the night shift group consumed less protein during the 4-day shifts than before the start of the study. Summary of the daily dietary intake of energy (a), protein (b), total fat (c), saturated fat (d), available carbohydrate (e) and sugars (f) calculated from 4 days of diet recordings at home before the study and on days 3-6 during the shifts. Data were compared by 2 -way repeated measures ANOVA. $* \mathrm{P}<0.05$ vs Pre night shift. Data are the mean \pm SEM for 6 day and 8 night shift participants.

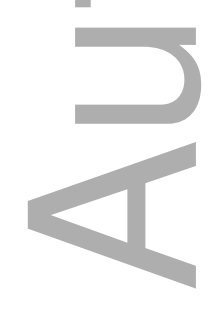

This article is protected by copyright. All rights reserved 


\section{Table 1}

Characteristics of the participants

$$
\text { Day shift Night shift Probability }
$$

Gender

Age (years)

4F 4M 5F 4M

Height (m)

$25.0 \pm 1.7$

$26.2 \pm 1.9$

$\mathrm{P}>0.05$

Screening MEQ score

$1.72 \pm 0.02$

$1.72 \pm 0.03$

$\mathrm{P}>0.05$

Screening DLMO

$49.1 \pm 1.1$

$52.3 \pm 2.4$

$\mathrm{P}>0.05$

$2153 \mathrm{~h} \pm 33 \mathrm{~m}$

$2135 \mathrm{~h} \pm 20 \mathrm{~m}$

$\mathrm{P}>0.05$

Pre study body weight (kg)

$67.3 \pm 3.13$

$65.0 \pm 5.3$

$\mathrm{P}>0.05$

Post study body weight $(\mathrm{kg})$

$67.4 \pm 3.2$

$65.3 \pm 5.4$

$\mathrm{P}>0.05$

Pre study BMI $\left(\mathrm{kg} \cdot \mathrm{m}^{-2}\right)$

$22.7 \pm 1.0$

$21.7 \pm 1.2$

$\mathrm{P}>0.05$

Post study BMI $\left(\mathrm{kg} \cdot \mathrm{m}^{-2}\right)$

$22.8 \pm 1.0$

$21.8 \pm 1.2$

$\mathrm{P}>0.05$

Pre study systolic blood pressure (mmHg)

$115.9 \pm 2.9$

$113.9 \pm 4.7$

$\mathrm{P}>0.05$

Pre study diastolic blood pressure $(\mathrm{mmHg})$

$70.4 \pm 1.9$

$70.9 \pm 2.2$

$\mathrm{P}>0.05$

Post study systolic blood pressure $(\mathrm{mmHg})$

$115.9 \pm 2.7$

$112.7 \pm 5.8$

$\mathrm{P}>0.05$

Post study diastolic blood pressure $(\mathrm{mmHg})$

$69.4 \pm 2.5$

$70.9 \pm 2.6$

$\mathrm{P}>0.05$

Screening $\mathrm{MEQ}=$ Screening Morningness/eveningness score. Screening DLMO = Screening Dim Light Melatonin Onset

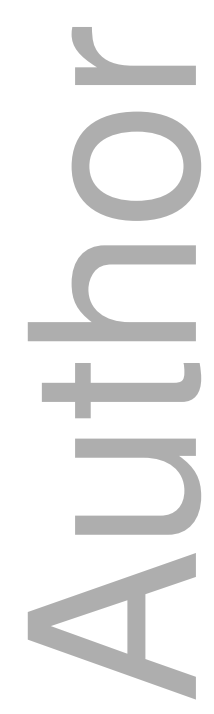

This article is protected by copyright. All rights reserved 

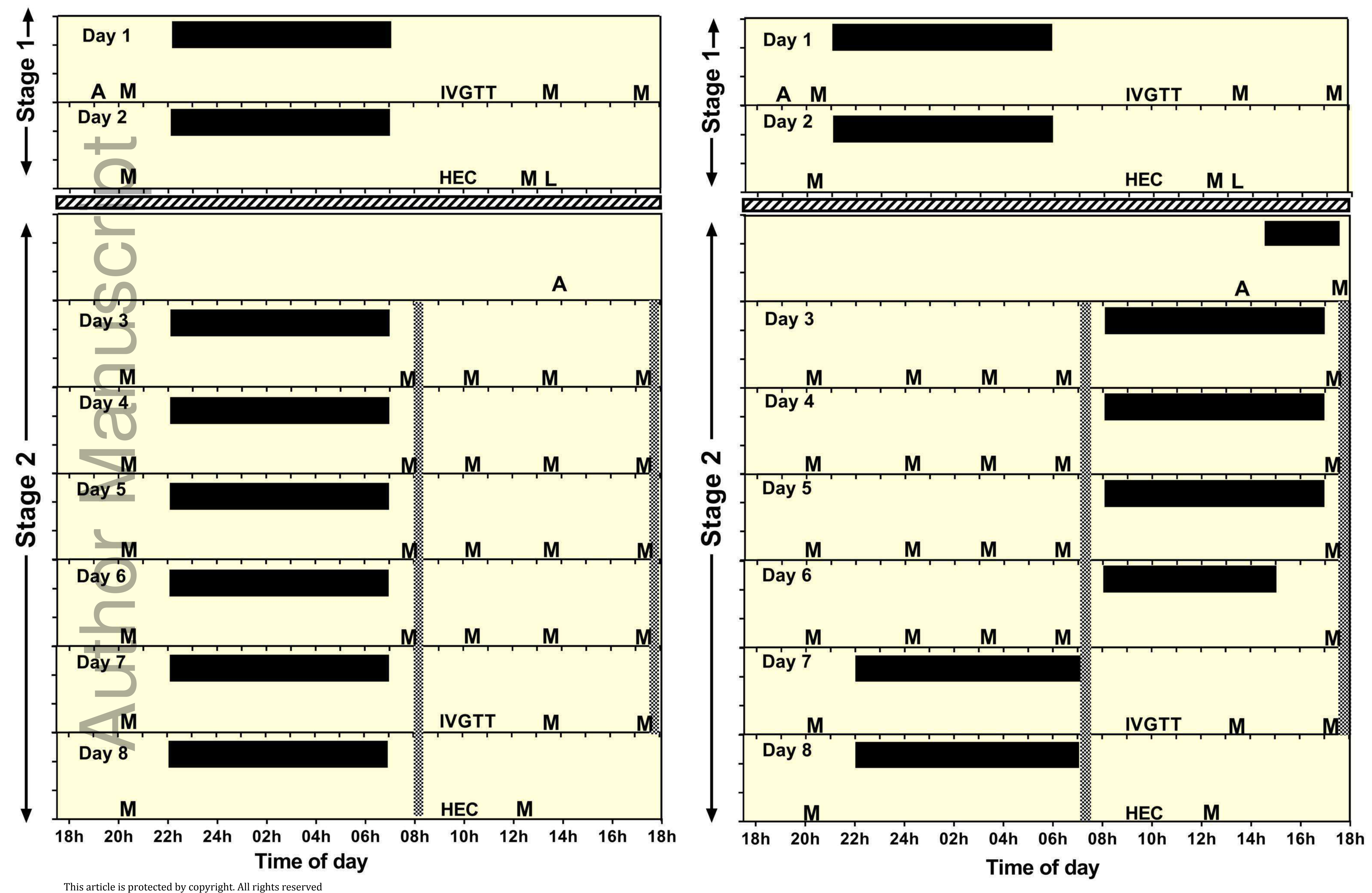
apha_13039_f2.pdf
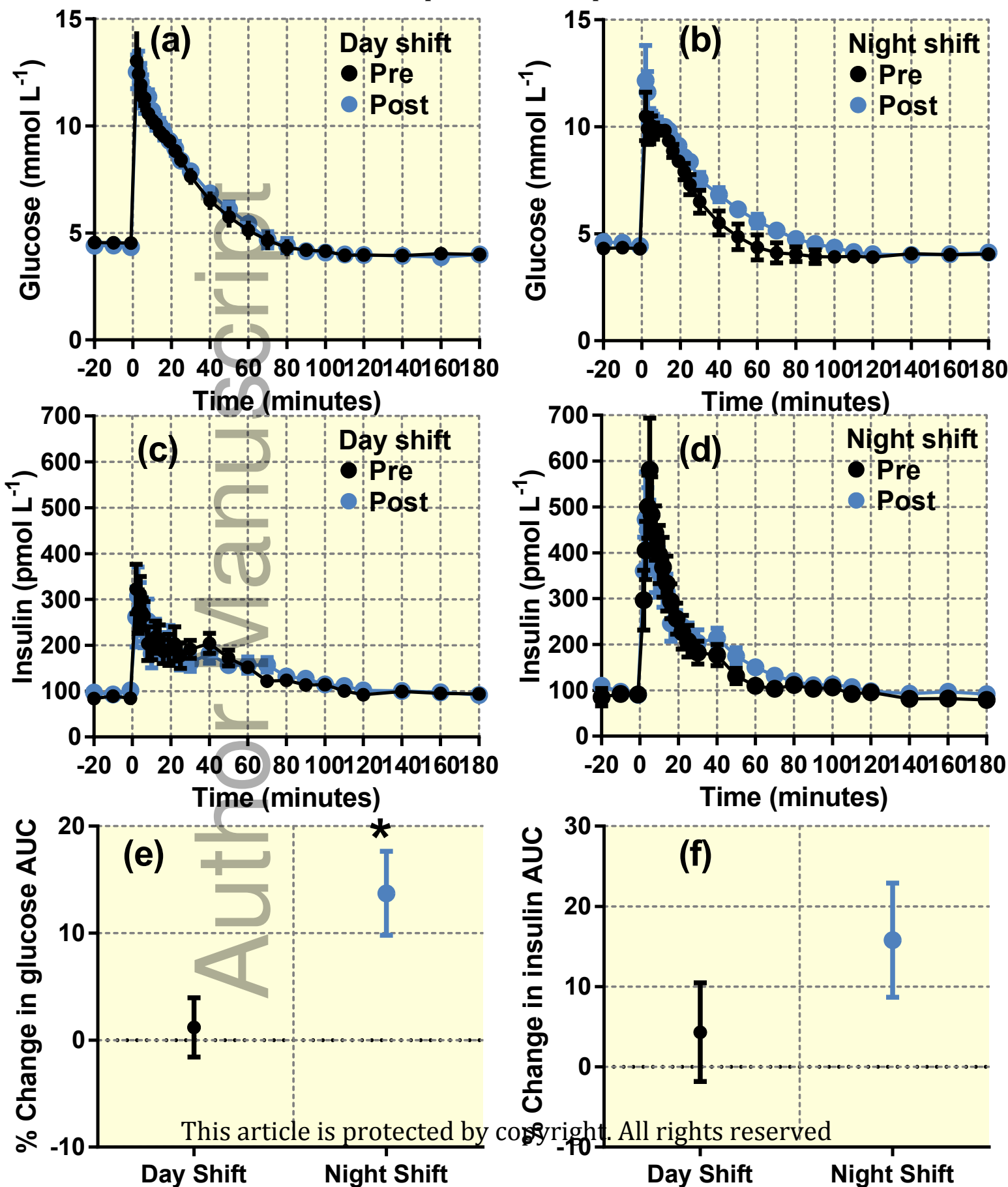

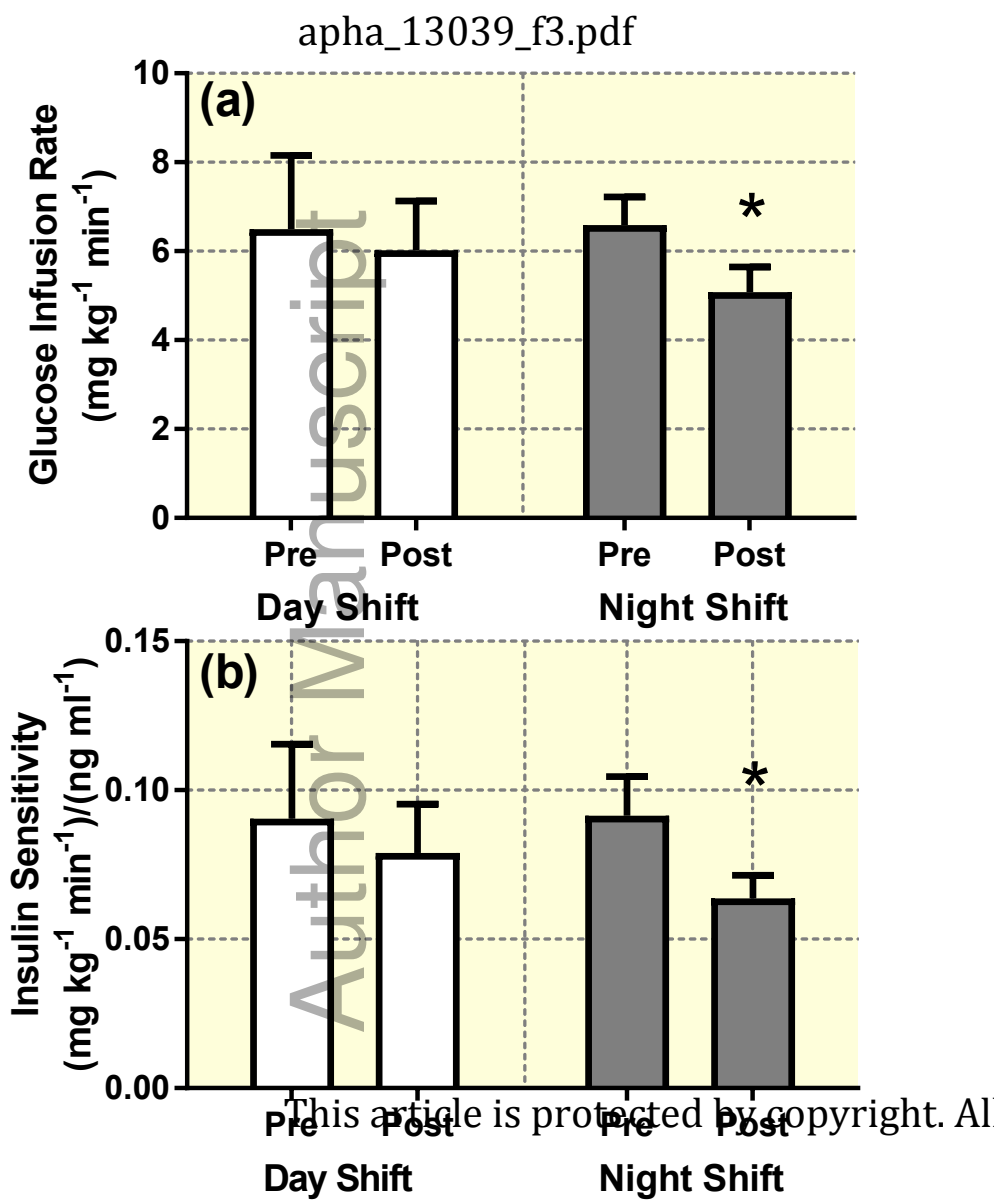

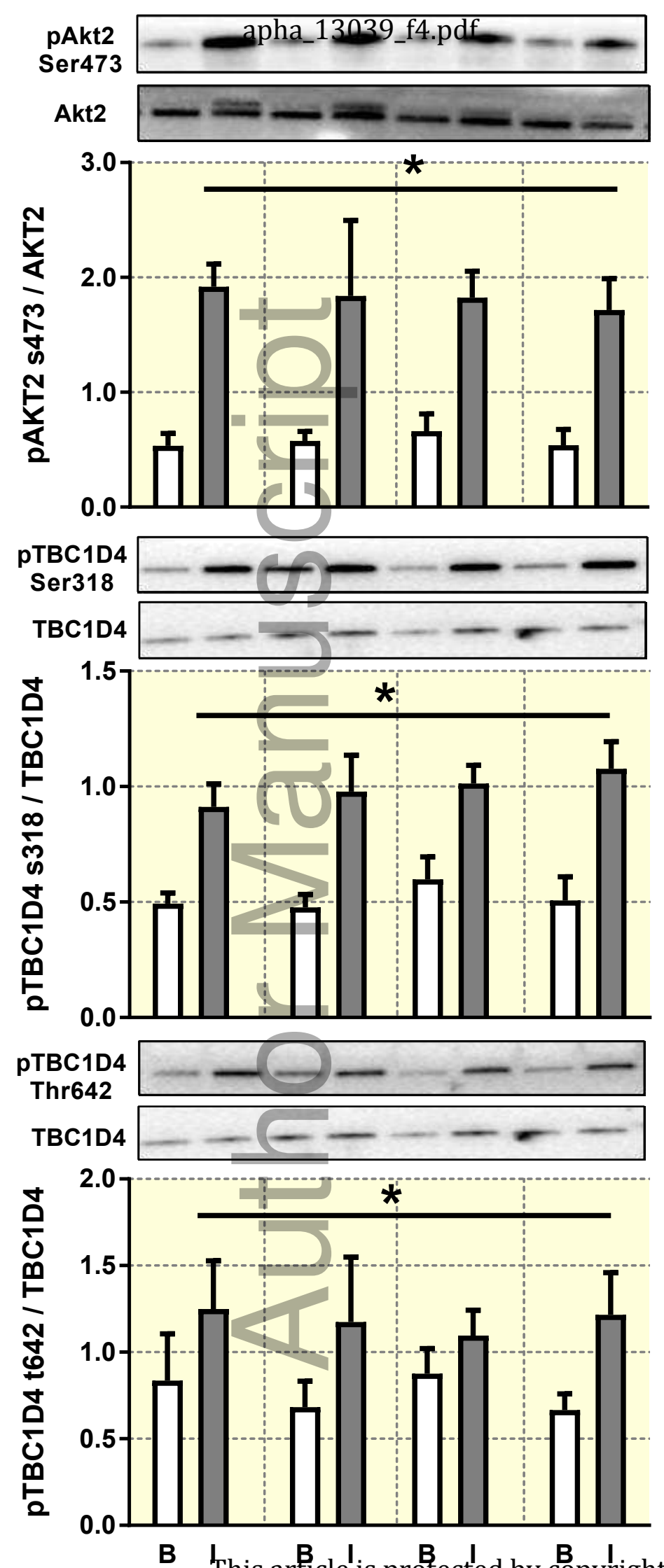

B This arpacle is proteted by copyright. All rig Day Shift Day Shift Night Shift Night Shift 


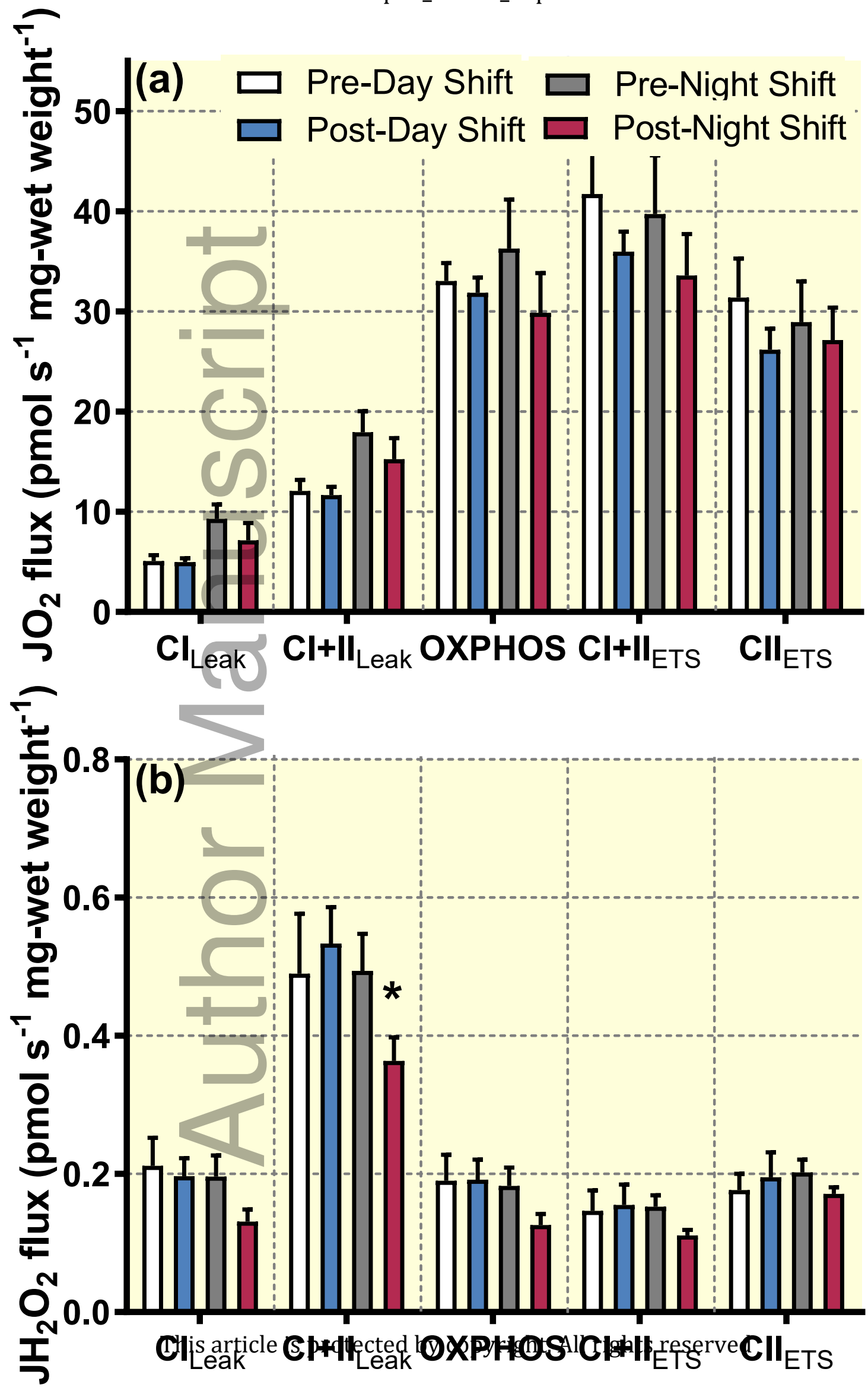




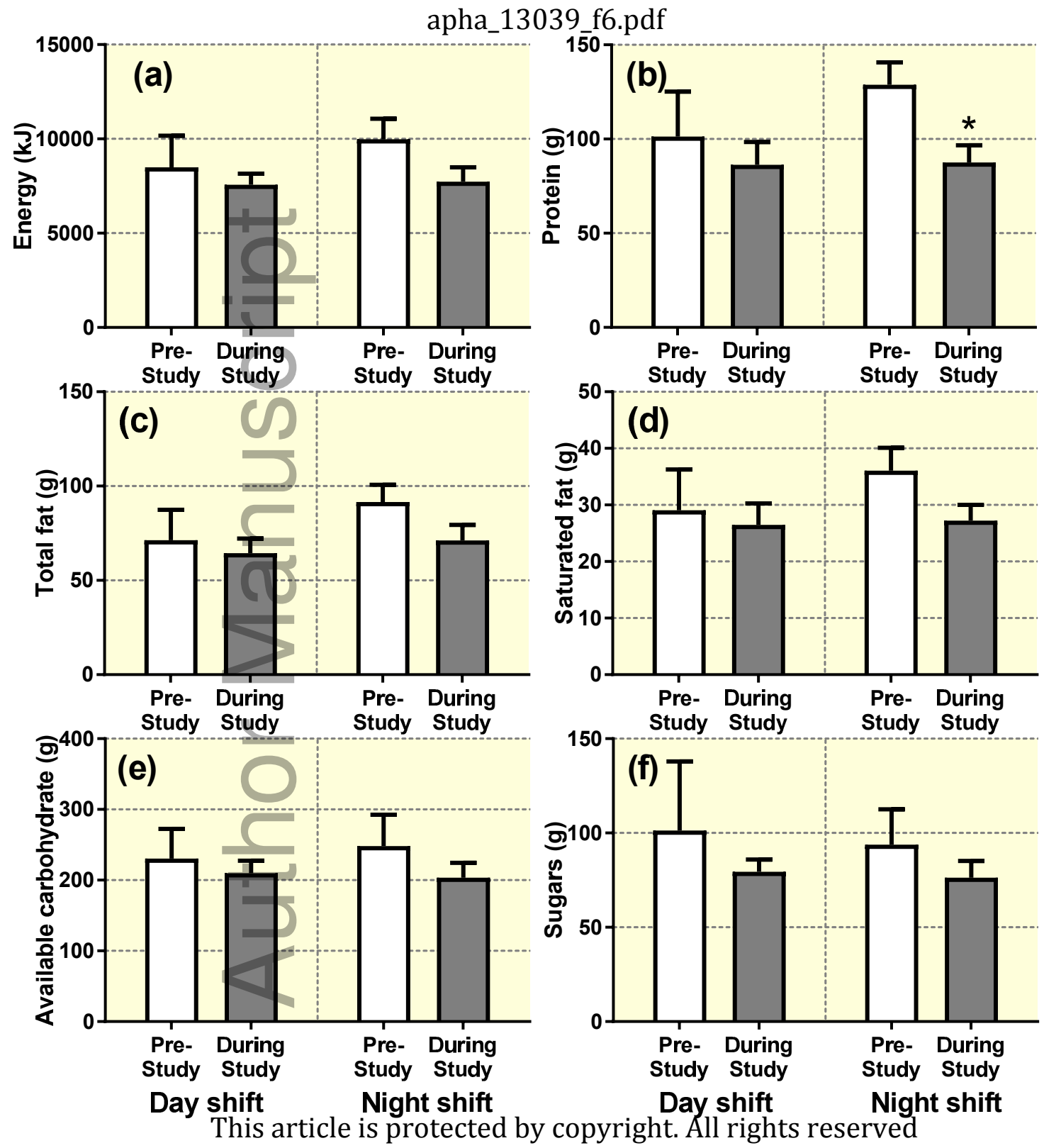




\section{University Library}

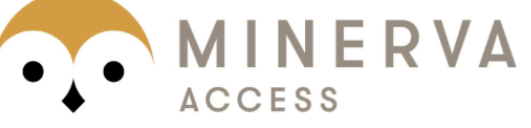

A gateway to Melbourne's research publications

Minerva Access is the Institutional Repository of The University of Melbourne

\section{Author/s:}

Bescos, R;Boden, MJ;Jackson, ML;Trewin, AJ;Marin, EC;Levinger, I;Garnham, A;Hiam, DS;Falcao-Tebas, F;Conte, F;Owens, JA;Kennaway, DJ;McConell, GK

Title:

Four days of simulated shift work reduces insulin sensitivity in humans

\section{Date:}

2018-06-01

\section{Citation:}

Bescos, R., Boden, M. J., Jackson, M. L., Trewin, A. J., Marin, E. C., Levinger, I., Garnham, A., Hiam, D. S., Falcao-Tebas, F., Conte, F., Owens, J. A., Kennaway, D. J. \& McConell, G. K. (2018). Four days of simulated shift work reduces insulin sensitivity in humans. ACTA PHYSIOLOGICA, 223 (2), https://doi.org/10.1111/apha.13039.

Persistent Link:

http://hdl.handle.net/11343/283600 